\title{
Hemodiyaliz ve periton diyalizi hastalarının Hepatit B aşısına karşı cevaplarının
} karşılaştırılması

\section{Comparison of responses to Hepatitis $B$ vaccine in patients with hemodialysis and peritoneal dialysis}

\author{
Ayşe Şeker Koçkara*, Ferhan Candan, Can Hüzmeli, Mansur Kayataş \\ Nefroloji Bilim Dalı (Dr. A. Ş. Koçkara, Prof. Dr. F. Candan, Dr. C. Hüzmeli, Prof. Dr. M. \\ Kayataş), Cumhuriyet Üniversitesi Tıp Fakültesi, TR-58140 Sivas
}

\begin{abstract}
Özet
Kronik böbrek hastalığı (KBH) olan hastaların çoğunda hem humoral hem de hücresel immünitede yetersizlik söz konusudur. Bu çalışmada KBH hastalarında çift doz rekombinant hepatit B aşısına karşı yanıt oranları ve renal replasman türünün antikor oluşumunda etkisi araştırılmıștır. Cumhuriyet Üniversitesi Tıp Fakültesi Hastanesi diyaliz merkezinde 51 hemodiyaliz (HD), 19 sürekli ayaktan periton diyalizi (SAPD) hastası rekombinant hepatit B aşısı ile $0,1,2$ ve 6 . ayda toplam dört kez aşılandı. Antikor yanıtları Anti-HBs titrasyon düzeylerine göre belirlendi. Aşııın son dozundan 1-3 ay sonra bakılan $10 \mathrm{mIU} / \mathrm{mL}$ 'nin üstündeki antikor titreleri aşıya yanıt olarak kabul edildi. Sonuçta HD ve SAPD hastalarının hepatit B aşısına verdikleri yanıtlar arasında anlamlı bir fark görülmedi (SAPD hastalarında \%84,2, HD hastalarında \%78,4 , $\mathrm{p}=0,591$ ). Diyaliz süresinin, cinsiyetin, yaşın, hemoglobin, total protein, albümin, c-reaktif protein (CRP), total kolesterol, trigliserid düzeyinin ve Anti-HCV(+)'liğinin hepatit B serokonversiyonuna etkisi de değerlendirildi. Bunlar arasında sadece yaşın $>50$ (yıl) olmasının yetersiz hepatit $\mathrm{B}$ serokonversiyonu ile ilişkili olduğu görüldü $(\mathrm{p}=0,037)$. Diğer parametrelerin hepatit $B$ serokonversiyonu üzerine etkisi gösterilemedi ( $p>0,05)$.
\end{abstract}

Anahtar sözcükler: Hepatit B, aşılama, hemodiyaliz, periton diyalizi

\begin{abstract}
There is generally a failure in humoral and cellular immunity in most of the patients with chronic renal failure (CRF). In this study, the rate of response of CRF patients to a double-dose hepatitis vaccination and the effect of renal replacement type on the formation of antibodies have been investigated. In our centre, 51 hemodialysis (HD) and 19 continuous ambulatory peritoneal dialysis (CAPD) patients were vaccinated with recombinant hepatitis B in the 0th, 1st, 2nd and 6th months. Antibody titrates over $10 \mathrm{mIU} / \mathrm{ml}$ seen 1-3 months after the vaccination were considered as a response to the vaccine. As a result, no meaningful difference has been observed between the responses HD and CAPD patients gave to the vaccine (CAPD 84.2\%, HD 78.4\%, $\mathrm{p}=0.591$ ). The effects of the duration of the dialysis, sex, age and hemoglobin, total protein, albumin, c-reactive protein (CRP), total cholesterol and triglyceride levels and the positivity of anti- $\mathrm{HCV}$ on hepatitis $\mathrm{B}$ seroconversion have also been evaluated. Of all these, only the age being over 50 has been seen to have a relationship with insufficient hepatitis B ceroconversion $(\mathrm{p}=0.037)$. The other parameters couldn't be shown to have an effect on the hepatitis B seroconversion ( $p>0.05$ ).
\end{abstract}

Keywords: Hepatitis B, vaccination, hemodialysis, peritoneal dialysis

Geliş tarihi/Received: 16 Şubat 2012; Kabul tarihi/Accepted: 28 Mayıs 2013

*iletişim adresi:

Dr. Ayşe Şeker Koçkara, Nefroloji Bilim Dalı, Cumhuriyet Tıp Fakültesi, TR-58140 Sivas. E-posta: doctrayse@gmail.com 


\section{Giriş}

Hepatit B virus (HBV) infeksiyonu tüm dünyada önemli sağlık sorunlarından bir tanesidir. Ülkemizde, Türk Nefroloji Derneği Kayıt Sistemi raporlarına göre, 2011 yılında hemodiyaliz hastalarında HBsAg pozitifliği oranı \%4,3'tür [1]. Kronik böbrek hastalığı $(\mathrm{KBH})$ hastalarında üremi nedeniyle immun sistemin baskılanması sonucu aşılara karşı yanıt yetersiz olmaktadır [2]. Sağlıklı kişilerde hepatit B aşısından sonra serokonversiyon oran $\% 90$ üzerinde iken $\mathrm{KBH}$ hastalarında bu oran \%50-80 arasındadır [3]. Literatürde, hepatit $\mathrm{B}$ antikoru oluşumu üzerinde cinsiyet, yaş, HCV pozitifliği ve albümin düzeyinin etkisi araştırılmış, bunların arasında ileri yaşın yetersiz antikor oluşumu ile anlamlı ilişkisi olduğu saptanmıştır [3-7]. Hemodiyaliz ve periton diyalizi hastalarının serokonversiyon oranını karşılaştıran çalışmalarda ise çelişskili sonuçlar elde edilmiştir [710].

$\mathrm{Bu}$ çalışmada, hemodiyaliz ve sürekli ayaktan periton diyalizi uygulanmakta olan KBH hastalarında çift doz rekombinant hepatit B aşısına karşı yanıt oranlarının araştıılması ve antikor oluşmasında rol olabilecek çeşitli faktörlerle renal replasman türünün etkisinin araştırılması amaçlanmıştır.

\section{Gereç ve yöntem}

Bu çalışmaya, Cumhuriyet Üniversitesi Tıp Fakültesi Hastanesi diyaliz merkezinde hemodiyaliz (HD) ve sürekli ayaktan periton diyalizi (SAPD) programında olan toplam 70 hasta alındı. HD hastalarına haftada 2 ya da 3 kez bikarbonatlı diyaliz uygulanıordu. Ortalama HD süresi 47,15 $\pm 35,2$ ay (6-204 ay) idi. SAPD (8000 cc/gün) yapan hastaların ortalama diyaliz süresi $56,57 \pm 32,95$ ay (15-118 ay) idi. Hastaların hiçbiri kortikosteroid veya bir başka immünsüpressif ilaç kullanmıyordu.

Hastalara 0,1, 2 ve 6 . aylarda çift doz $(40 \mu \mathrm{g})$ olmak üzere toplam dört kez rekombinant DNA kökenli HBV aşısı deltoid kas içine intramusküler olarak yapıldı. Aşılar önerilen ticari koşullara göre saklandı. Çalışmamızdaki sonuç antikor değerleri, dört doz aşılama sonrasinda her bir olgunun serumunda, ELISA ile saptanan Anti-HBs titrasyon düzeylerine göre belirlendi. Aşının son dozundan 1-3 ay sonra $10 \mathrm{mIU} / \mathrm{ml}$ nin üstündeki antikor titreleri aşıya yanıt olarak değerlendirildi. Aşılamanın başlangıcındaki hemoglobin, C-Reaktif protein (CRP), total protein, albümin, total kolesterol düzeyi ve Anti $\mathrm{HCV}(+)$ 'liği kaydedildi. Bu biyokimyasal parametrelerin ve cinsiyet, yaş, diyaliz süresi ve diyaliz tipinin antikor yanıtı üzerindeki etkileri incelendi.

Çalışmamızın verileri SPSS (ver:14.0) programına yüklenerek, verilerin değerlendirilmesinde parametrik test varsayımları yerine getirilemediği için Mann Whitney U test, Ki-kare testi ve Fisher'in kesin Ki-kare testi kullanılmış ve yanılma düzeyi 0,05 olarak alınmıştır.

\section{Bulgular}

Çalışmaya 51'i hemodiyaliz (31 kadın, 20 erkek), 19'u periton diyalizi (13 kadın, 6 erkek) olmak üzere toplam 70 hasta alındı. Hastaların demografik ve biyokimyasal özellikleri Tablo 1'de gösterilmiştir. Gruplar arasında yaş, cinsiyet, biyokimyasal veriler ve diyaliz süresi (HD-SAPD uygulanan hastalarda) açısından fark yoktu.

Yetmiş hastanın 14 (\%20)'ünde aşıya yanıt sağlanamazken; 56 (\%80) hastada yeterli antikor yanıtı sağlandı. SAPD hastalarında \%84,2, HD hastalarında $\% 78,4$ oranında yeterli antikor yanıtı sağlandı. Antikor oluşumu açısından SAPD ve HD hastalarında istatistiksel fark saptanmadi $(\mathrm{p}=0.591$; Tablo 1$)$.

HD hastalarında 6 anti-HCV(+), SAPD hastalarında 3 Anti-HCV(+) hasta vardı. Anti$\mathrm{HCV}(+)$ olan hastaların tümünde serokonversiyon gelişti. Anti-HCV $(+)^{\prime}$ 'liği ile hepatit $\mathrm{B}$ antikoru oluşması arasında anlamlı bir ilişki saptanmadı $(\mathrm{p}=0,188)$. HBs antikoru pozitif olan hastalarda \%16,1 oranında Anti-HCV $(+)$ 'liği saptanırken, antikor negatif olanlarda Anti-HCV $(+)$ 'liği saptanamamıştır. Bu yüzdenin önemsiz çıkmasının nedeni antikor negatif olan hasta sayısının az olmasından kaynaklanmaktadır (Tablo 2). 
Tablo 1. Hastaların demografik ve biyokimyasal özellikleri.

\begin{tabular}{llll}
\hline & HD & SAPD & P değeri \\
\hline Say1 & 51 & 19 & \\
Cinsiyet (E/K) & $20 / 31$ & $6 / 13$ & 0,557 \\
Yaş (y1l) & $52,28 \pm 15,80$ & $45,73 \pm 13,37$ & 0,051 \\
Diyaliz süresi (ay) & $47,15 \pm 35,20$ & $56,57 \pm 32,95$ & 0,193 \\
Anti-HCV(+) & $6(\% 11,8)$ & $3(\% 15,8)$ & 0,696 \\
Hemoglobin (g/dL) & $11,15 \pm 1,78$ & $11,41 \pm 2,33$ & 0,552 \\
Albumin (g/dL) & $3,15 \pm 0,75$ & $3,31 \pm 0,51$ & 0,483 \\
Total protein (g/dL) & $6,60 \pm 0,95$ & $6,58 \pm 0,78$ & 0,682 \\
CRP & $41,24 \pm 63,40$ & $17,45 \pm 27,76$ & 0,118 \\
Total kolesterol (mg/dL) & $170,84 \pm 45,15$ & $177,94 \pm 29,83$ & 0,291 \\
Trigliserid (mg/dL) & $186,70 \pm 130,83$ & $143,26 \pm 73,71$ & 0,154 \\
Hbs antikor (+) & $40(\% 78,4)$ & $16(\% 84,2)$ & 0,591 \\
\hline
\end{tabular}

Hastaların cinsiyeti, hemoglobin, albümin, total protein, CRP, total kolesterol, trigliserid düzeyleri ve ortalama diyaliz süreleri açısından ile hepatit $\mathrm{B}$ antikor yanıtı arasında istatistiksel bir fark bulunamadi $(\mathrm{p}>0,05)$.

Tablo 2. Hepatit B aşılaması sonunda Anti-HBs serokonversiyonu olan (Gurup I) ve olmayan (Gurup II) hastaların demografik ve biyokimyasal özelliklerinin karşılaştırılması.

\begin{tabular}{llll}
\hline Değişken & Gurup I (n=56) & Gurup II (n=14) & P değeri \\
\hline Ort. yaş \pm SD (yıl) & $49,37 \pm 16,06$ & $56,14 \pm 11,26$ & 0,217 \\
Yaş (>50), n (\%) & $31(55,4)$ & $12(85,7)$ & 0,037 \\
Kadın cinsiyet, n (\%) & $35(62,5)$ & $9(64,3)$ & 0,902 \\
Ort. diyaliz süresi \pm SD (ay) & $47,07 \pm 34,79$ & $60,28 \pm 33,07$ & 0,095 \\
Ort. hemoglobin \pm SD (g/dL) & $11,09 \pm 1,77$ & $11,72 \pm 2,47$ & 0,217 \\
Ort. albumin \pm SD (g/dL) & $3,20 \pm 0,74$ & $3,16 \pm 0,48$ & 0,517 \\
Ort. total protein \pm SD (g/dL) & $6,57 \pm 0,91$ & $6,70 \pm 0,90$ & 0,532 \\
Ort. Kan C-reaktif protein (mg/L) & $38,29 \pm 62,49$ & $20,77 \pm 18,55$ & 0,612 \\
Ort. Kan kolesterolü \pm SD (mg/dL) & $173,17 \pm 42,22$ & $171,14 \pm 39,78$ & 0,877 \\
Ort. Kan trigliseridi \pm SD (mg/dL) & $182,76 \pm 126.60$ & $143,50 \pm 78,88$ & 0,172 \\
Anti-HCV $(+), n(\%)$ & $9(\% 16,1)$ & $0(0,0)$ & 0,188 \\
\hline Diyaliz tipi, n (\%) & & & \\
Hemodiyaliz & $40(71,4)$ & $11(78,6)$ & 0,591 \\
Sürekli ayaktan periton diyalizi & $16(28,6)$ & $3(21,4)$ & \\
\hline
\end{tabular}

Guruplar yaş ortalaması açısından karşılaştırıldığında serokonversiyon yönünden fark bulunamazken, yaş >50 (yıl) alındığında serokonversiyon gelişmesi açısından fark önemli bulunmuştur $(\mathrm{p}<0,05) .50$ yaş altındaki hastalarda serokonversiyon gelişmesi oranı \% $\% 92,6$ iken, 50 yaş üstündeki hastalarda serokonversiyon oranı \%72,1'dir (Tablo 2).

\section{Tartışma}

KBH hastalarında immünsupresyon nedeniyle aşılamaya yanıt azalmıştır. Diyaliz hastalarında, normal kişilere göre aşılama sonrası daha düşük antikor titresi saptanır [11, 12]. Bu hastalarda T-lenfosit ve antijen sunan hücrelerde fonksiyon bozukluğu olduğu düşünülmektedir [13-15]. Bazı çalışmalarda diyalizsiz takip edilen $\mathrm{KBH}$ hastalarında daha yüksek antikor cevabının elde edilmesi, böbrek yetmezliğinin şiddeti ile immün cevabın korele olduğunu düşündürmektedir $[13,16,17]$. KBH hastalarında hepatit $\mathrm{B}$ aşılamasına yeterli cevap alınabilmesi için yüksek doz ve daha sık enjeksiyon yapılması önerilmiştir [10, 18]. İmmün cevabı artırmak için çift doz aşılama yapılması, düşük antikor titresi elde edilirse booster doz yapılması [19-23], enjeksiyon şeklinin değiştirilmesi (intradermal veya intramüsküler), immün sistemi indükleyen ajanların eklenmesi [24-27] ve hepatit A ve B aşısının kombine verilmesi [28] gibi çeşitli yöntemler uygulanmıştır. 
HD ve periton diyalizi (PD) hastalarında serokonversiyon oranını araştıran az sayıda çalışma vardır. Khan ve ark. [8], $50 \mathrm{HD}$ ve $47 \mathrm{PD}$ hastasının hepatit B aşısına verdikleri cevabı karşılaştırmışlar ve $0,1,2$ ve 6 . aylarda çift doz hepatit B aşısı uygulandıktan sonra serokonversiyon oranını HD hastalarında \%74, PD hastalarında ise \%53 olarak bulmuşlardır. Bel'eed ve ark. [9], 0,1, 2 ve 3. aylarda uygulanan hepatit B aşısından sonra serokonversiyon oranını HD ve PD hastalarında eşit (\%66) bulmuşlardır. Başka bir araştırmada da $27 \mathrm{HD}, 15 \mathrm{PD}$ hastasının serokonversiyon oranı karşılaştırılmış, PD'de \%93,3, HD'de ise \% 66,7 bulunduğu bildirilmiştir ( $\mathrm{p}=0,053)$. Bu çalışmada hastalar 3 guruba ayrılmış ve her guruba ayrı aşılama şeması uygulanmıştır, bu yüzden antikor cevabını diyaliz türüne göre karşılaştırmak uygun değildir [10]. Ülkemizde Erciyes Üniversitesi Hastanesi'nde yapılan bir çalışmada 29 HD, 11 SAPD ve 15 prediyaliz hastasında, serokonversiyon oranı karşılaştırılmış, aralarında fark görülmemiştir [29]. Düzce Üniversitesi Hastanesi'nde yapılan başka bir çalışmada da HD ve SAPD hastaları arasında antikor yanıtı açısından fark saptanmamıştır [30]. Literatürde bu konuda yapılan çalışmalar çelişkilidir. Biz de çalışmamızda 63 HD ve 17 SAPD hastasına 0, 1, 2 ve 6. aylarda çift doz $(40 \mu \mathrm{g})$ olmak üzere toplam dört kez hepatit B aşısı uyguladık ve her iki grupta benzer serokonversiyon oranı saptadık (HD: \%78,4, SAPD: \% 84,2). Çalışmamızda diyaliz süresinin, cinsiyetin ve anti-HCV $(+)$ 'liğinin de hepatit $\mathrm{B}$ serokonversiyonuna etkisi gösterilemedi. KBH hastalarında hepatit B aşısına antikor cevabı multifaktöriyeldir. Yaş, albümin düzeyi, hepatit $\mathrm{C}$ enfeksiyonu, eritropoetin eksikliği, ineffektif diyaliz antikor cevabını etkileyebilmektedir. Fabrizi ve ark. [7] tarafından yapılan bir metaanalizde diyaliz türünün aşı yanıtı üzerine etkisinin olmadığı, genç hastalarda aşı yanıtının daha yükssek olduğu bildirilmiştir. Bizim çalışmamızda da serokonversiyon olan ve olmayan grupların yaş ortalamaları arasında istatistiksel olarak fark olmamasına rağmen, 50 yaş üzeri hastaların daha düşük antikor yanıtı oluşturdukları görüldü. Literatürdeki bazı çalışmalarda, malnutrisyon ve albümin düzeyinin antikor cevabını azalttığ gösterilmiştir [31, 32]. Bizim çalışmamızda albümin, total protein, CRP ve kolesterol düzeylerinin antikor yanıtı ile ilişkisi gösterilemedi.

Sonuç olarak KBH hastalarının immün sistemleri baskılanmış olduğundan enfeksiyonlara yatkın olup, aynı zamanda aşılamaya yanıtları zayıftır. Centers for Disease Control and Prevention (CDC), hemodiyaliz hastalarının 0, 1, 2 ve 6. aylarda çift doz rekombinant hepatit B aşısı ile aşılanmalarını, Anti-HBs antikor düzeyinin izlenerek, antikor düzeyi 10 $\mathrm{mIU} / \mathrm{ml}$ 'nin altına düşerse booster doz aşı yapılmasını önermiştir [33]. Yapılan çalışmaların çoğunda HD ve PD hastaları arasında antikor yanıtı açısından fark görülmemiştir. Bu yüzden HD, PD ve prediyaliz hastalarda çift doz rekombinant hepatit $\mathrm{B}$ aşısı uygulanmalıdır. KBH'da süre ilerledikçe immün sistem baskılanması artacağından, bu hastalara tanı koyulduğunda erken dönemde hepatit B aşısı yapılmalıdır.

\section{Kaynaklar}

1. Türk Nefroloji Derneği Ulusal Hemodiyaliz, Transplantasyon ve nefroloji kayıt sistemi raporu 2011.

2. Unger JK, Peters H. Hepatitis B in chronic kidney disease: moving toward effective prevention. Kidney Int 2008; 73: 799-801.

3. Liu YL, Kao MT, Huang CC. A comparison of responsiveness to hepatitis B vaccination in patients on hemodialysis and peritoneal dialysis. Vaccine 2005; 23: 3957-60.

4. Peces R, de la Torre M, Alcázar R, Urra JM. Prospective analysis of the factors influencing the antibody response to hepatitis $\mathrm{B}$ vaccine in hemodialysis patients. Am J Kidney Dis 1997; 29: 239-45.

5. Navarro JF, Teruel JL, Mateos M, Ortuno J. Hepatitis C virus infection decreases the effective antibody response to hepatitis $\mathrm{B}$ vaccine in hemodialysis patients. Clin Nephrol 1994; 41: 113-6.

6. Stevens CE, Alter HJ, Taylor PE, Zang EA, Harley EJ, Szmuness W. Hepatitis B vaccine in patients receiving hemodialysis. Immunogenicity and efficacy. N Engl J Med 1984; 311: 496-501. 
7. Fabrizi F, Martin P, Dixit V, Bunnapradist S, Dulai G. Meta-analysis: the effect of age on immunological response to hepatitis $\mathrm{B}$ vaccine in end-stage renal disease. Aliment Pharmacol Ther 2004; 20: 1053-62.

8. Khan AN, Bernardini J, Rault RM, Piraino B. Low seroconversion with hepatitis B vaccination in peritoneal dialysis patients. Perit Dial Int 1996; 16: 370-3.

9. Bel'eed K, Wright M, Eadington D, Farr M, Sellars L. Vaccination against hepatitis B infection in patients with end stage renal disease. Postgrad Med J 2002; 78: 538-40.

10. Mitwalli A. Responsiveness to hepatitis B vaccine in immunocompromised patients by doubling the dose scheduling. Nephron 1996; 73: 417-20.

11. Rodby RA, Trenholme GM. Vaccination of the dialysis patient. Semin Dial 1991; 4: 102-5.

12. Dinits-Pensy M, Forrest GN, Cross AS, Hise MK. The use of vaccines in adult patients with renal disease. Am J Kidney Dis 2005; 46: 997.

13. Eleftheriadis T, Antoniadi G, Liakopoulos V, Kartsios C, Stefanidis I. Disturbances of acquired immunity in hemodialysis patients. Semin Dial 2007; 20: 440-51.

14. Litjens NH, Huisman M, van den Dorpel M, Betjes MG. Impaired immune responses and antigen-specific memory $\mathrm{CD} 4+\mathrm{T}$ cells in hemodialysis patients. $\mathrm{J}$ Am Soc Nephrol 2008; 19: 1483-90.

15. Agrawal S, Gollapudi P, Elahimehr R, Pahl MV, Vaziri ND. Effects of end-stage renal disease and haemodialysis on dendritic cell subsets and basal and LPSstimulated cytokine production. Nephrol Dial Transplant 2010; 25: 737-46.

16. Buti M, Viladomiu L, Jardi R, Olmos A, Rodriguez JA, Bartolome J, Esteban R, Guardia J. Long-term immunogenicity and efficacy of hepatitis B vaccine in hemodialysis patients. Am J Nephrol 1992; 12: 144-7.

17. Seaworth B, Drucker J, Starling J, Drucker R, Stevens C, Hamilton J. Hepatitis B vaccines in patients with chronic renal failure before dialysis. J Infect Dis 1988; 157: 332-7.

18. el-Reshaid K, al-Mufti S, Johny KV, Sugathan TN. Comparison of two immunization schedules with recombinant hepatitis $\mathrm{B}$ vaccine and natural immunity acquired by hepatitis B infection in dialysis patients. Vaccine 1994; 12: 223-34.

19. Marangi AL, Giordano R, Montanaro A, De Padova F, Schiavone MG, Dongiovanni G, Basile C. Hepatitis B virus infection in chronic uremia: longterm follow-up of a two-step integrated protocol of vaccination. Am J Kidney Dis 1994; 23: 537-42.

20. Donati D, Gastaldi L. Controlled trial of thymopentin in hemodialysis patients who fail to respond to hepatitis B vaccination. Nephron 1988; 50: 133-6.

21. Propst T, Propst A, Lhotta K, Vogel W, König P. Reinforced intradermal hepatitis B vaccination in hemodialysis patients is superior in antibody response to intramuscular or subcutaneous vaccination. Am J Kidney Dis 1998; 32: 10415 .

22. Evans TG, Schiff M, Graves B, Agosti J, Barritt ML, Garner D, Holley JL. The safety and efficacy of GM-CSF as an adjuvant in hepatitis B vaccination of chronic hemodialysis patients who have failed primary vaccination. Clin Nephrol 2000; 54: 138-42.

23. Charest AF, McDougall J, Goldstein MB. A randomized comparison of intradermal and intramuscular vaccination against hepatitis $\mathrm{B}$ virus in incident chronic hemodialysis patients. Am J Kidney Dis 2000; 36: 976-82.

24. Barraclough KA, Wiggins KJ, Hawley CM, van Eps CL, Mudge DW, Johnson DW, Whitby M, Carpenter S, Playford EG. Intradermal versus intramuscular hepatitis B vaccination in hemodialysis patients: A prospective open-label randomized controlled trial in nonresponders to primary vaccination. Am J Kidney Dis 2009; 54: 95-103. 
25. Kong NC, Beran J, Kee SA, Miguel JL, Sánchez C, Bayas JM, Vilella A, CalboTorrecillas F, López de Novales E, Srinivasa K, Stoffel M, Hoet B. A new adjuvant improves the immune response to hepatitis $\mathrm{B}$ vaccine in hemodialysis patients. Kidney Int 2008; 73: 856-62.

26. Surquin M, Tielemans CL, Kulcsár I, Ryba M, Vörös P, Mat O, Treille S, Dhaene M, Stolear JC, Kuriyakose SO, Leyssen MX, Houard SA. Rapid, enhanced, and persistent protection of patients with renal insufficiency by ASO2(V)-adjuvanted hepatitis B vaccine. Kidney Int 2010; 77: 247-55.

27. Alavian SM, Tabatabaei SV. Effects of oral levamisole as an adjuvant to hepatitis $B$ vaccine in adults with end-stage renal disease: a meta-analysis of controlled clinical trials. Clin Ther 2010; 32: 1-10.

28. Tung J, Carlisle E, Smieja M, Kim PT, Lee CH. A randomized clinical trial of immunization with combined hepatitis $\mathrm{A}$ and $\mathrm{B}$ versus hepatitis $\mathrm{B}$ alone for hepatitis B seroprotection in hemodialysis patients. Am J Kidney Dis 2010; 56: 713-9.

29. Doğukan A, Taşkapan H, Güven M, Tokgöz B, Oymak O, Utaş C. Prediyaliz, hemodiyaliz ve sürekli ayaktan periton diyalizi hastalarında çift doz hepatit B aşısına yanıt. Türk Nefroloji Diyaliz ve Transplantasyon Dergisi 1999; 4: 192-4.

30. Alçelik A, Bicik Z, Bahçebaşı T, Açıkgöz E, Yıldırım M, Önder E. Hemodiyaliz ve ayaktan periton diyalizi hastalarının hepatit $\mathrm{B}$ aşısına karşı immün yanıtlarının değerlendirilmesi. İstanbul Tıp Fakültesi Dergisi 2007; 70: 39-43.

31. Kara IH, Yılmaz ME, Suner A, Kadiroglu AK, Işıkoğlu B. The evaluation of immune responses that occur after HBV infection and HBV vaccination in hemodialysis patients. Vaccine 2004; 22: 3963-7.

32. Fernandez E, Betriu MA, Gómez R, Montoliu J. Response to the hepatitis B virus vaccine in haemodialysis patients: influence of malnutrition and its importance as a risk factor for morbidity and mortality. Nephrol Dial Transplant 1996; 11: 1559-63.

33. Centers for Disease Control and Prevention (CDC) Recommendations for preventing transmission of infections among chronic hemodialysis patients. MMWR Recomm Rep, 50 (RR-5) 2001; pp: 1-43. 